\title{
The Contact and Transient Dynamic Analysis of Gear Meshing with ANSYS
}

\author{
Xing Zou, Chengwen Yang, Baolin Liu \\ College of Nuclear Technology and Automation Engineering, Chengdu University of Technology, Chengdu, China \\ Email: mxy_1995@sina.com
}

How to cite this paper: Zou, X., Yang, C.W. and Liu, B.L. (2020) The Contact and Transient Dynamic Analysis of Gear Meshing with ANSYS. Open Access Library Journal, 7: e6771.

https://doi.org/10.4236/oalib.1106771

Received: September 2, 2020

Accepted: September 27, 2020

Published: September 30, 2020

Copyright $\odot 2020$ by author(s) and Open Access Library Inc.

This work is licensed under the Creative Commons Attribution International License (CC BY 4.0).

http://creativecommons.org/licenses/by/4.0/

(c) (i) Open Access

\begin{abstract}
The paper describes the dynamic characteristic and fatigue life of the gear meshing. Use the ANSYS to deal with the problem of motion errors which are the result of the wear and the curve caused by the rough surface of the gear generated by the low machining accuracy in the process. And through the analysis, the value and the changing trend of the equivalent stress, fatigue life, and fatigue sensitivity with different friction coefficients can be known. Then it provides an important theoretical basis to strengthen the strength and stability, reduce the deformation of the gear, and improve fatigue life.
\end{abstract}

\section{Subject Areas}

Mechanical Engineering

Keywords

ANSYS, Gear Meshing, Contact Dynamic, Friction Coefficient, Fatigue Life

\section{Introduction}

Gear transmission is the most widely applied transmissions among the mechanical transmissions. It has a strict transmission ratio and transfers smoothly. Because the transmission ratio can be kept constant, the gear transmission is widely applied in many kinds of gearboxes, heavy equipment, and other areas [1].

The common methods of gear processing can be divided into copying and generating by the theory. The gear processed by copying has low accuracy and the accuracy is always below 11 degree. Because the generating bases on the theory of gear meshing, the accuracy is higher. During the transmission process of gears with varieties accuracy, the different friction coefficient between the faces of gears has a direct effect on the gears' life. So, during the transmission, 
the face of gear often becomes invalid. Lightly there are gear wearing and gear pitting, and worse there are gear bonding even tooth fracture. These failures all affect the transmission ratio and the stability of the gear transmission system so that the life of the mechanical system decreases.

Scholars at home and abroad have conducted in-depth research on this issue and have achieved fruitful results. Chaari et al. used the Weber method material mechanics to analyze the effect of tooth surface flaking on the meshing stiffness by the gear deformation and hertz contact deformation [2]. Ma et al., based on Chaari's research, studied the influence of the tooth surface flaking on the gear vibration characteristic signal [3]. But above research, from the machining quality and accuracy, has not analyzed the effect of the gear wearing produced during the gear meshing on single gear stress and fatigue life. Some scholars have established many dynamic characteristic mathematical models of the gear meshing [4] [5]. But most of them neglected the effect of the friction between the gear faces on the gear transmission. Although others considered the gear faces friction, these models assigned the friction on the gear faces averagely and the stress change trend of the gear meshing does not obtain [6].

To solve these problems, in this paper, a pair of ordinary straight tooth cylindrical involute gears have been taken as research object. The 3-D geometry model was established by UG, and the ANSYS was used to analyze the transient contact dynamic characteristics. The deformation, stress change, and fatigue change have been obtained from the analysis. During the process of the gear meshing transmission, it provides a common conclusion and solution for the great force of the gear tooth, serves deformation and fatigue failure.

\section{Theory Analysis}

\subsection{Transient Dynamics Analysis}

Transient dynamics analysis is used to determine the dynamic response of the time-varying load structure. The transient dynamics analysis can determine the time-varying displacement, strain, stress, and force response of the structure under the random combination of the steady load, transient load, and simple harmonic load.

The motion equation of transient dynamics analysis:

$$
[M]\{\ddot{u}\}+[C]\{\dot{u}\}+[K]\{u\}=\{F(t)\}
$$

The load $\{F(t)\}$ is the function of time. $[M]$ is the mass matrix. [C] is the damping matrix. $[K]$ is the stiffness matrix. $\{u\}$ is the displacement matrix.

\subsection{Contact Analysis}

Based on the linear static structure analysis, the driving wheel and the driven wheel are set as elastic bodies A and B respectively. When the A and B contacts, there will be innumerable contact points and they can make respective dis- 
placement $\left\{U^{A}\right\}$ and $\left\{U^{B}\right\}$ under the external load $\left\{P^{A}\right\}$ and $\left\{P^{B}\right\}$. According to the basic theory of Finite Element, the balanced equation can be obtained:

$$
\begin{aligned}
& {\left[K^{A}\right]\left\{U^{A}\right\}=\left\{P^{A}\right\}+\left\{R^{A}\right\}} \\
& {\left[K^{B}\right]\left\{U^{B}\right\}=\left\{P^{B}\right\}+\left\{R^{B}\right\}}
\end{aligned}
$$

$\left[K^{A}\right]$ and $\left[K^{B}\right]$ are the stiffness matrixes of $A$ and $B ;\left\{U^{A}\right\}$ and $\left\{U^{B}\right\}$ are the nodes displacement vectors; $\left\{P^{A}\right\}$ and $\left\{P^{B}\right\}$ are the external load of $A$ and $\mathrm{B} ;\left\{R^{A}\right\}$ and $\left\{R^{B}\right\}$ are the contact force vectors of $\mathrm{A}$ and $\mathrm{B}$.

According to the analysis of the balanced equations, once the characteristics of materials and external load have been determined, the $\left[K^{A}\right],\left[K^{B}\right],\left\{P^{A}\right\}$ and $\left\{P^{B}\right\}$ also have been determined. But there are still four unknown parameters that cannot be solved by two equations. So the elastic body contact nature should be added, and different natures correspond to different displacement and supplementary equations of contact force relationship. Last the balanced equations are solved.

For the process of solving equations with ANSYS, the stiffness matrixes $[K]$ and external load $\{P\}$ are taken into the balanced equations, and according to the hypothesis of contact nature, the contact displacement $\{U\}$ and contact force $\{R\}$ are solved. Then the obtained $\{U\}$ and $\{R\}$ are compared with the hypothesis contact nature. If they are not the same, other hypotheses will be needed and the results will be calculated again until the results are the same with the hypothesis [7].

\section{Simulation Analysis}

\subsection{Geometry Model Establishment}

In this paper, all the gears are a pair of standard mounting external meshing and standard spur gears. The main parameters are $Z_{1}=22, Z_{2}=33, \alpha=20^{\circ}$, $h_{a}^{*}=a, \quad m=2.5 \mathrm{~mm}, C^{*}=0.25, \quad b=20 \mathrm{~mm}$. Among these gears, $Z_{1}$ was the driving wheel and $Z_{2}$ was driven wheel.

The CG toolbox in UG was used to set gear meshing. In order to reduce the difficulty of mesh dividing and the requirements for computer hardware and increase the speed of calculation, under the condition of guaranteeing the accuracy, the keyways and chamfers on gears were omitted. The three-D model is shown in Figure 1.

\subsection{Finite Element Model Establishment}

The established gear engagement model was imported into ANSYS. The material was defined as structure steel. Considering the real working condition of gears, the type of contact of the contact gear surface was set as Frictional, and the friction coefficient was initialized as 0.01 . Among this, the Contac was set as a driving wheel and Target was set as a driven wheel [8], shown as Figure 2. In order to guarantee the accuracy and correctness of the results, in the mesh dividing, 


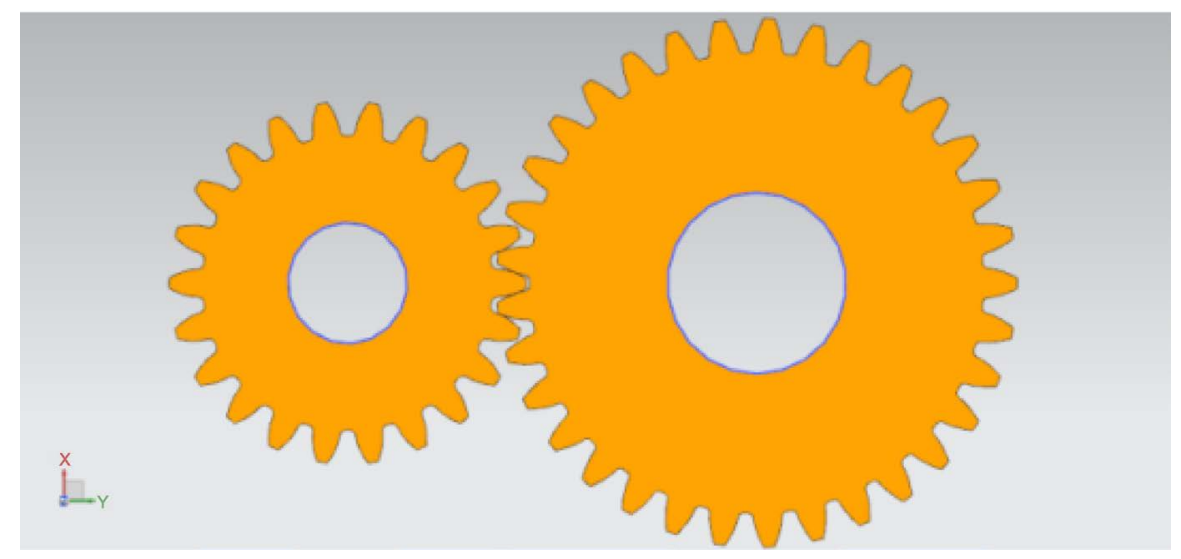

Figure 1. Gear meshing 3D model.

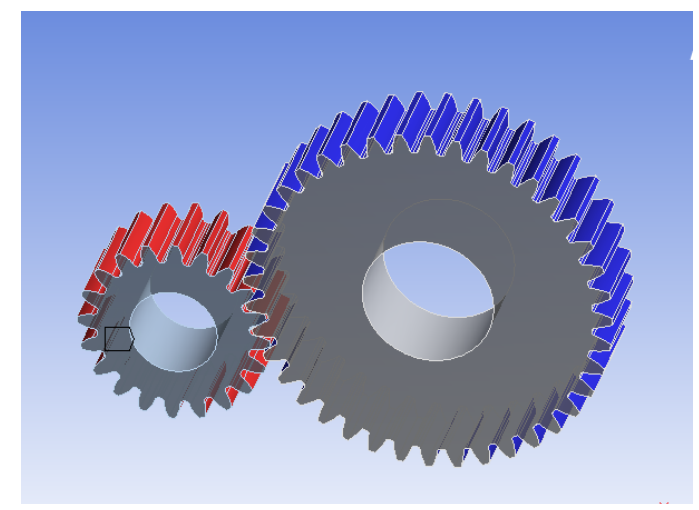

Figure 2. Gear set contacts.

the 3D tetrahedral mesh intelligent division was used. So there were 23,519 notes and 4065 elements, shown as Figure 3. According to the working condition, 10 $\mathrm{N} \cdot \mathrm{m}$ constant drag torque was added on the driven wheel and $60 \mathrm{r} / \mathrm{s}$ constant speed was added on the driving wheel, shown as Figure 4.

\section{Results and Discussion}

\subsection{Results of Transient Contact Dynamics Analysis}

According to the calculation of the finite element model, the calculation results were imported into the postprocessor and the equivalent stress distribution cloud diagram during gear meshing with the friction coefficient 0.01 was obtained, shown as Figure 5.

Changing the friction coefficient in the contact set to simulate the gear meshing in different processing accuracy, the equivalent stress distribution cloud diagram during gear meshing with the friction coefficient $0.05,0.1,0.15$, and 0.2 could be obtained, shown in Figure 6.

From Figure 6, when the friction coefficient keeps static, the maximum stress is shown in the root of the driving wheel during the gear meshing.

With the increasing of the friction coefficient, it means that the processing accuracy of the gear surface gets decreased, the surface gets roughness and the 


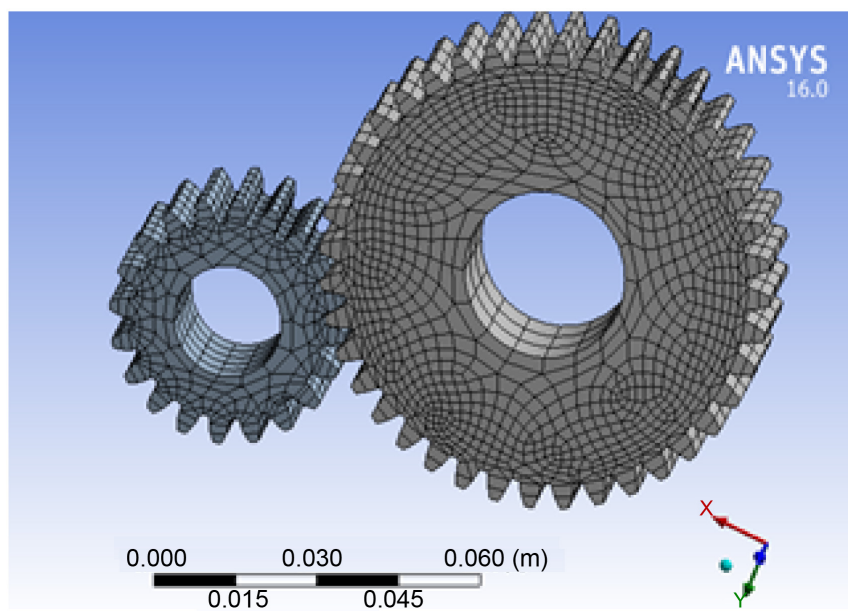

Figure 3. Meshing dividing.

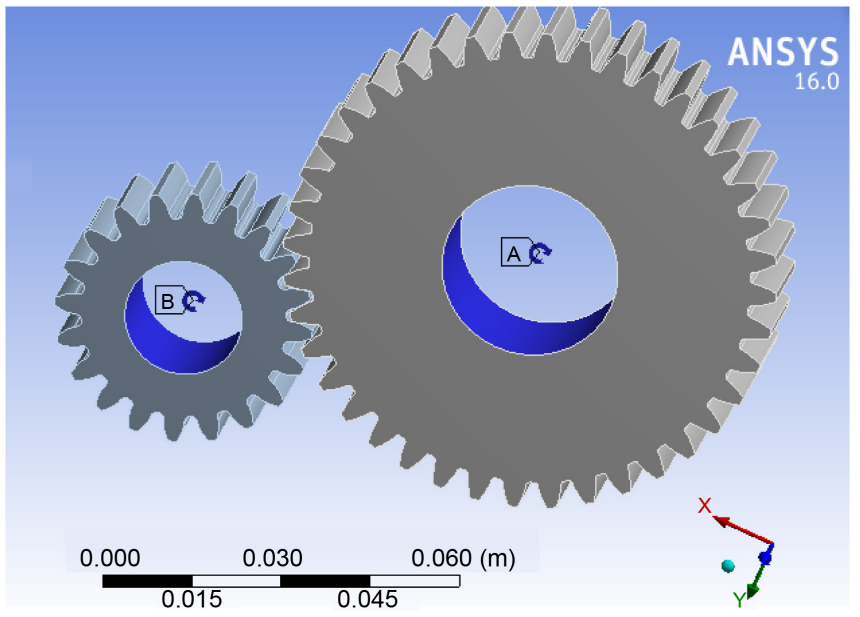

Figure 4. Setting up revolving speed and resisting moment.

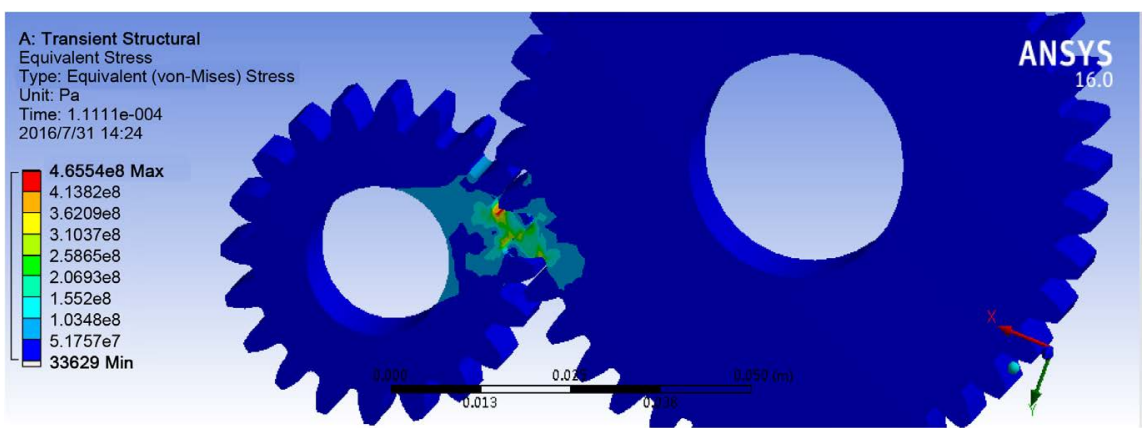

Figure 5. The cloud diagram of equivalent stress with the friction coefficient 0.01 .

wear of gear gets increased. So the equivalent stress in the area of gear meshing increases obviously and the minimum equivalent stress in the external area of the gear engagement decreases.

The reason is the increase of the friction coefficient, and it causes the friction drag increased during the relative motion of the gear faces. It makes the gear faces in the gear meshing area sustains more load. 


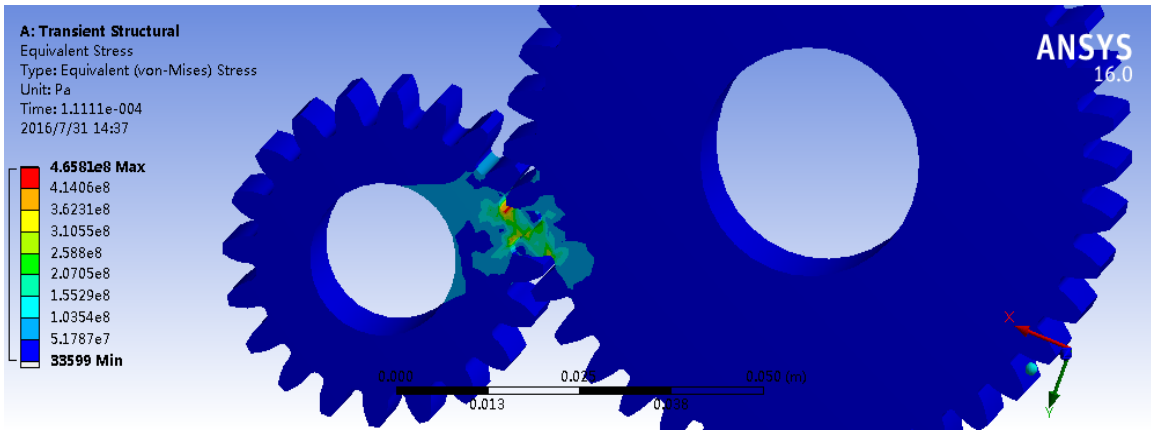

(a)

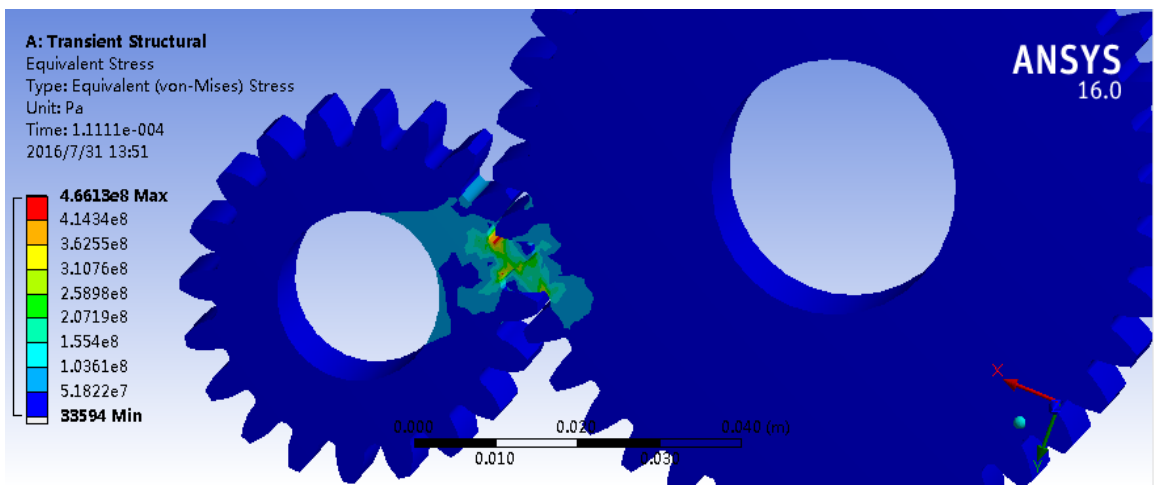

(b)

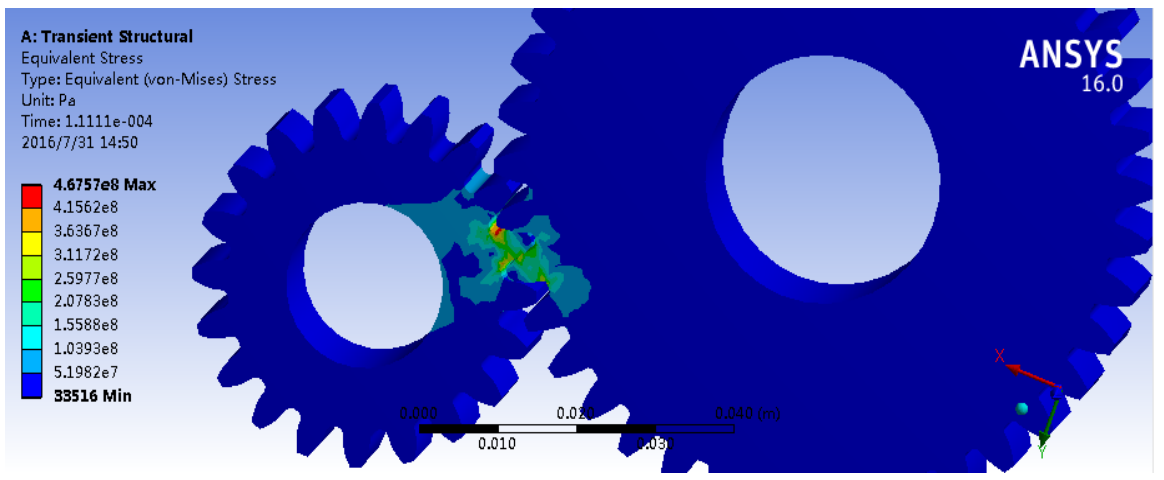

(c)

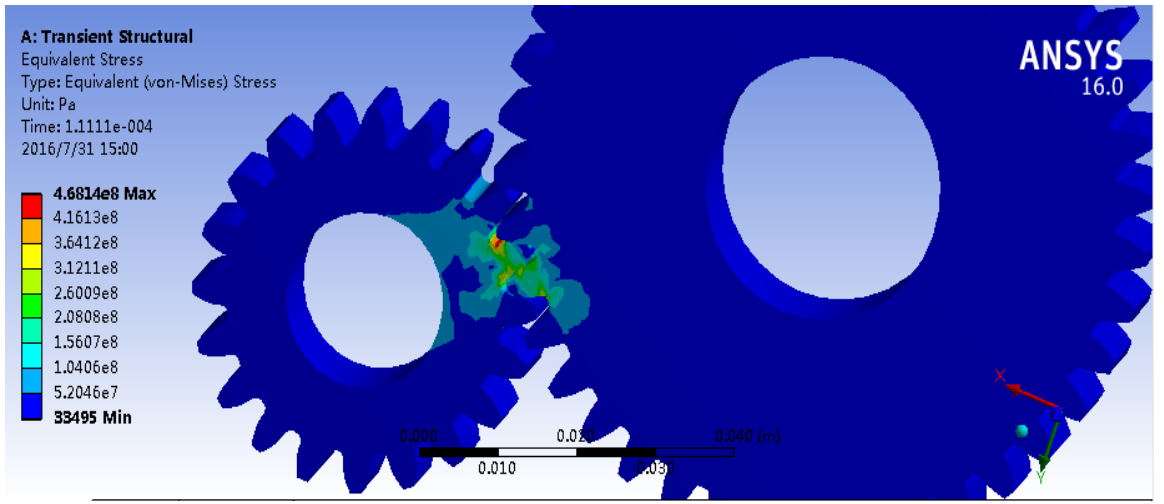

(d)

Figure 6. The cloud diagram of equivalent stress with the different friction coefficient. (a) Friction coefficient 0.05, (b) Friction coefficient 0.1, (c) Friction coefficient 0.15, (d) Friction coefficient 0.2 . 


\subsection{Fatigue Life Analysis}

The calculation results were imported into the Fatigue Tool. In addition, the type of fatigue load was set as Zero-Based and the fatigue stress factor was also set as 0.8 , shown as Figure 7. Although the dynamic stress component is the fundamental reason for fatigue failure, the static stress component, average stress, also has some effect on the fatigue limit. Within a certain static stress range, the compression static stress can increase the fatigue limitation and the tensile static stress can decrease the fatigue limit. Because the load is a Zero-Based cyclic load and its average stress is not zero, the Goodman Average Stress theory can be used.

After post-processing, the fatigue life and sensitivity with friction coefficient $0.01,0.05,0.1,0.15$, and 0.2 were obtained, shown as Figure 8 .

When the friction coefficient keeps static, from the fatigue life cloud diagram, the tooth root got fatigue failure first. With the increase of friction coefficient, the minimum fatigue life was getting shorter. So it meant that the processing accuracy gets lower, the gear gets fatigue invalid more easily.

In the curve of fatigue sensitivity, the abscissa represents the number of cycles. The whole graph represents, under a certain number of cycles, the maximum fatigue stress which can be sustained by the components with the alternating loads. When the friction coefficient gets higher and the cycle number of alternating loads keeps static, the maximum fatigue stress sustained by the gear decreases.

During the process of the gear meshing, the relative sliding speed at the nodal line during the driving and driven wheels are opposite, which means that the sliding speed at the nodal line is zero. At this time, the friction coefficient at the nodal line is the static friction coefficient. But the static friction coefficient is higher than the dynamic friction coefficient. According to the surface friction equation, when the friction coefficient is higher, and it causes the friction is higher. So the possibility of fatigue failure is higher [9]:

$$
F=f \cdot N
$$

\section{Constant Amplitude Load}

Zero-Based

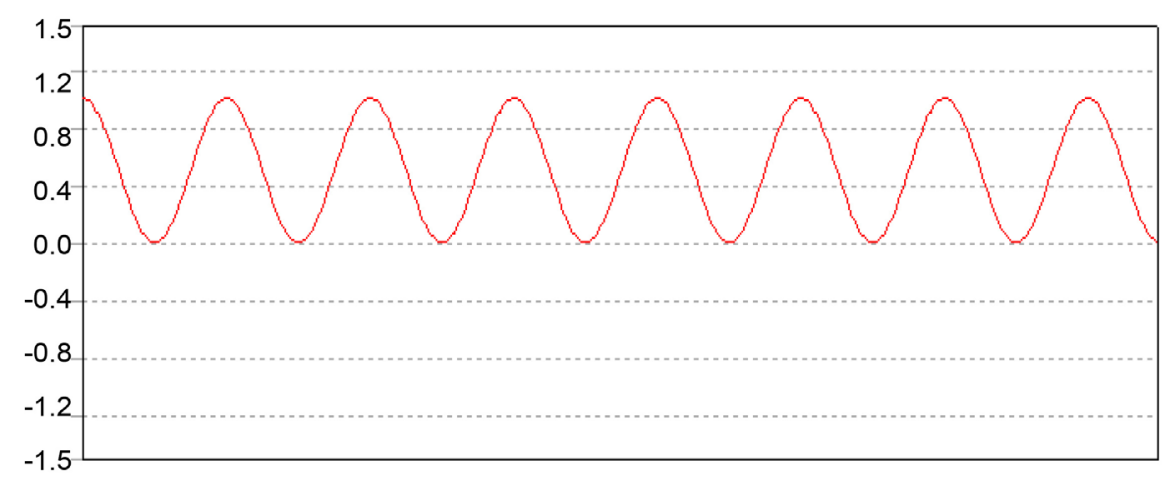

Figure 7. Zero-based load. 


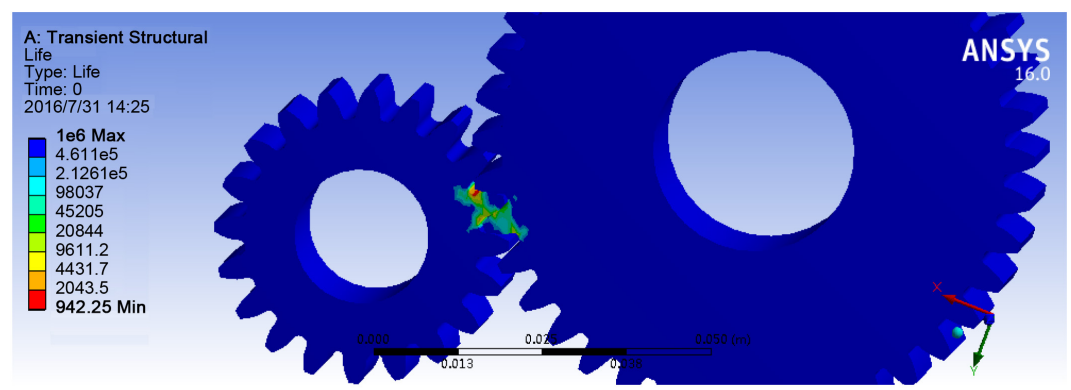

(a)

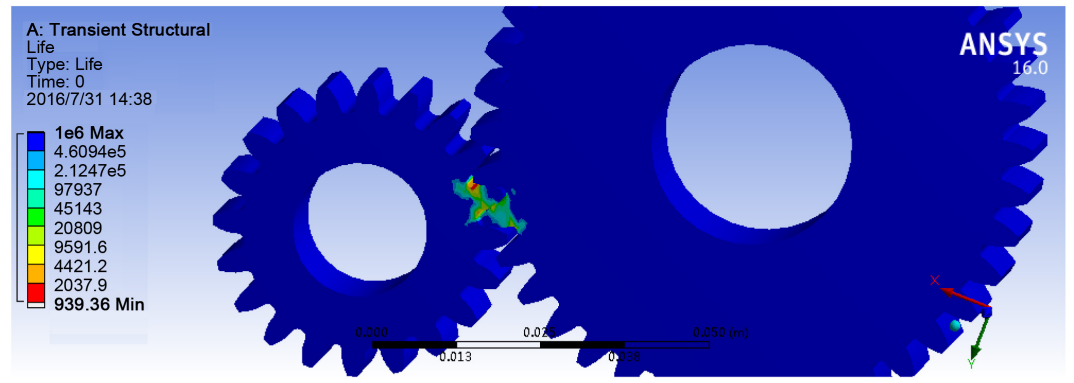

(b)

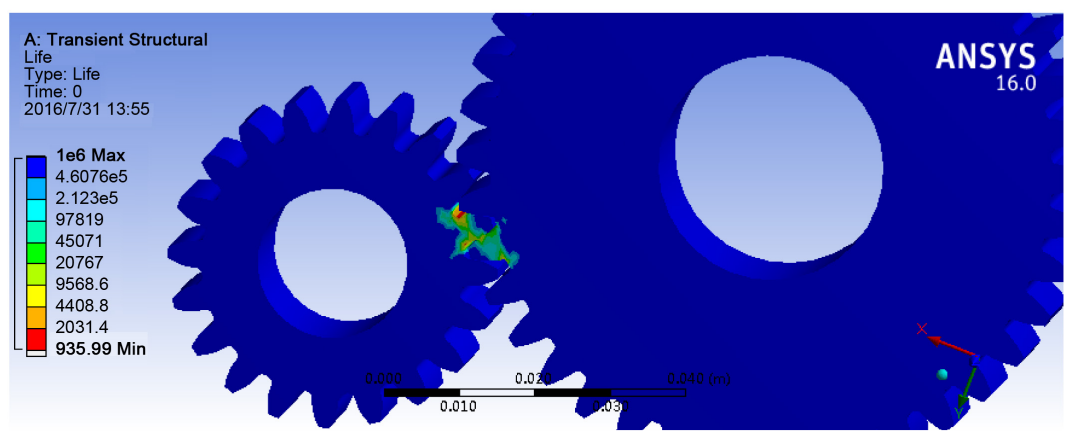

(c)

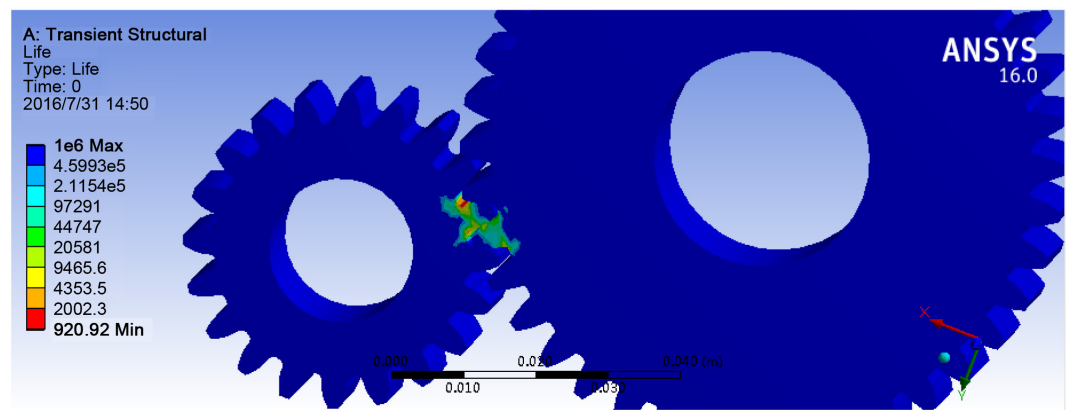

(d)
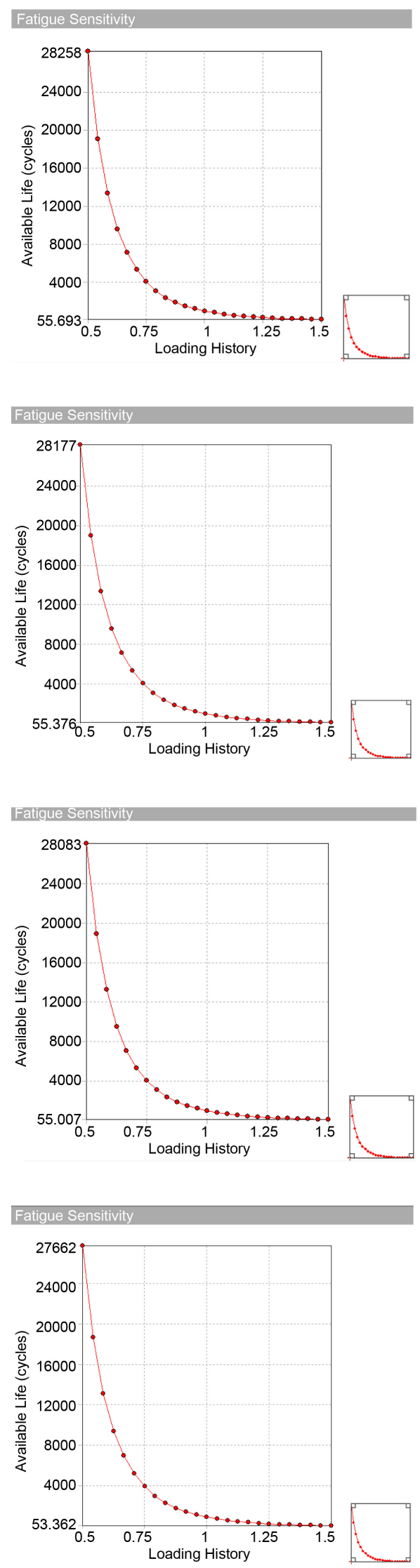

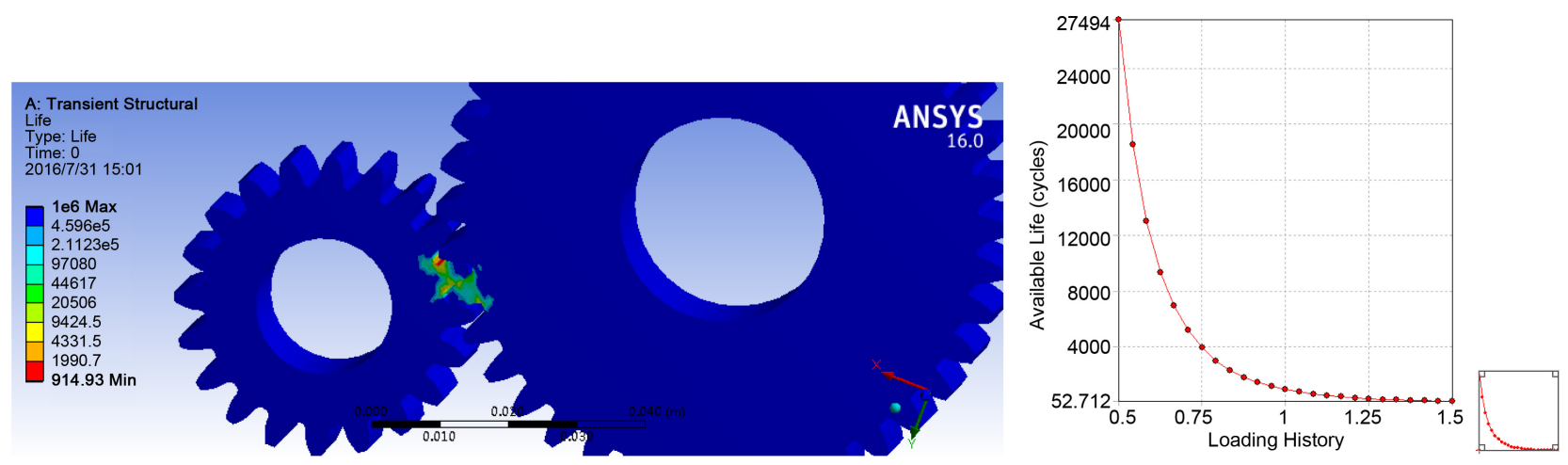

(e)

Figure 8. The cloud diagram of fatigue life and fatigue sensitivity with the different friction coefficient. (a) The cloud diagram of fatigue life and fatigue sensitivity with the friction coefficient 0.01 . (b) The cloud diagram of fatigue life and fatigue sensitivity with the friction coefficient 0.05 . (c) The cloud diagram of fatigue life and fatigue sensitivity with the friction coefficient 0.1 . (d) The cloud diagram of fatigue life and fatigue sensitivity with the friction coefficient 0.15 . (e) The cloud diagram of fatigue life and fatigue sensitivity with the friction coefficient 0.2 .

Within the increasing of the friction coefficient, the change limitation of the load is getting lower. It means that, under the condition of the critical fatigue life, a higher friction coefficient causes lower processing accuracy. Then it causes the load range sustained by the components to get smaller, so, under the condition of a long time running, fatigue failure happens more easily.

\section{Conclusions}

According to the transient contact dynamic analysis of the gear meshing, the stress distribution, change the trend, and the range of fatigue failure has been obtained. The conclusions are shown as follow:

According to the transient contact dynamic analysis, the position of the maximum stress during the gear meshing has been obtained; changing the friction coefficient of the contact area to simulate the different processing accuracy, the trend of equivalent stress change of the gear meshing has also been obtained.

After the analysis of the gear meshing fatigue life, the area, under the different friction coefficient during the gear meshing, where the fatigue failure happens more easily has been obtained. And the limit value of the load change under the critical fatigue condition has been obtained.

This can provide a theoretical basis for the analysis of the strength analysis, fatigue life prediction, and the adjustment of the processing plans.

\section{Acknowledgements}

The authors express their sincere thanks to the workmates giving a lot of help to this study.

\section{Conflicts of Interest}

The authors declare no conflicts of interest regarding the publication of this paper. 


\section{References}

[1] Jiang, S.L., Fan, B.H. and Jiang, S.B. (2015) Discussion on Cylindrical Gear Transmission in Transient Dynamic Analysis. Coal Mine Machinery, No. 8, 115-157.

[2] Chaari, F., Baccar, W., Abbes, M.S., et al. (2008) Effect of Spalling or Tooth Breakage on Gearmesh Stiffness and Dynamic Response of a One-Stage Spur Gear Transmission. European Journal of Mechanics-A/Solids, 27, 691-705.

https://doi.org/10.1016/j.euromechsol.2007.11.005

[3] Ma, R., Chen, Y. and Cao, Q. (2012) Research on Dynamics and Fault Mechanism of Spur Gear Pair with Spalling Defect. Journal of Sound \& Vibration, 331, 2097-2109. https://doi.org/10.1016/j.jsv.2011.12.010

[4] Xiao, Z.M., Xun, L.R. and Cao, J.X. (2020) Influence of Crack Fault on the Dynamical Characteristics of a Planetary Gear Transmission System. Journal of Vibration and Shock, 39, 188-194.

[5] Cheng, Z., Hu, N., Zuo, M., et al. (2012) Crack Level Estimation Approach for Planetary Gear Sets Based on Simulation Signal and GRA. Journal of Sound Vibration, 331, 5853-5863. https://doi.org/10.1016/j.jsv.2012.07.035

[6] Wang, Y., Wang, Q.B. and Zhang, Y.M. (2013) Helical Gear System Dynamic Character Analysis Based on Sliding Friction. Machinery Design \& Manufacture, No. 10, 22-25.

[7] Yang, F., Sun, S.Q., Yu, J.H. and Man, W.W. (2010) Exact Analysis of Gear Contact Stress in Meshing Process. Journal of Mechanical Transmission, 34, 56-59.

[8] Zhang, Y. (2014) ANSYS Workbench 15.0 Finite Element Analysis. China Machine Press, Beijing.

[9] Xia, Y.Q., et al. (2002) The Influence of Friction Coefficient on the Contact Fatigue Life of Gear. Journal of Mechanical Transmission, 26, 48-49. 